MCINTOSH, I. B., SWANSON, V., POWER, K. G., et al (1998) Anxiety and health problems related to air travel. Journal of Travel Medicine, $\mathbf{5}$,

original papers population of Minnesota. Acta

Psychiatrica/Neurologica

Scandinavica, Supplementum 4

SHAPIRO, S. (1976) A study of psychiatric syndromes manifested at an international airport. Comprehensive Psychiatry, 17, 453-456.

sychiatric behavior disorders at an international airport. Archives of Environmental Health, 17, 360-365.

ØDEGAARD, 0. (1932) Emigration and insanity. A study of mental disease among the Norwegian-born
— (1982) Airport wandering as a psychotic symptom. Psychiatria Clinica, 15, 173-176.
SPEIZER, C., RENNIE, C. J. \& BRETON, H. (1989) Prevalence of in-flight medical emergencies on commercial airlines. Annals of Emergency Medicine, 18, 26-29.

SPENCE, S. A. (1995) Personality disorder and police section 136 in Westminster: a retrospective analysis

*Udo Wieshmann PhD, TheWalton Centre for Neurology and Neurosurgery, Lower Lane, Fazakerley, Liverpool L9 7LJ M. Anjoyeb B. B. Lucas MRCPsych, The Hillingdon Hospital, Mental Health Unit, Pield Heath Road, Uxbridge, Middlesex UB5 3NN of 65 assessments over six month. Medicine, Science and the Law, 35 $48-52$

WORLD HEALTH ORGANIZATION (1992) The ICD-10 Classification of Mental and Behavioural Disorders. Geneva: WHO

\title{
Developing a child and adolescent mental health service for children with learning disabilities
}

\author{
AIMS AND METHOD \\ We discuss the development of a \\ service for children with learning \\ disabilities within a child and \\ adolescent mental health team using \\ the Health Advisory Service Together \\ We Stand tier system. The paper also \\ includes an audit of the service \\ 8 months after it was started.
}

\author{
RESULTS \\ We present a model of service that \\ has proved successful to date. We \\ give details from the audit of the \\ service, its aims, funding, referral \\ numbers, sources, types and criteria.
}

\begin{abstract}
CLINICAL IMPLICATIONS
The audit suggests that the aims of the service are being achieved but given the fact that the numbers of new referrals significantly outweigh the discharge rate, it is concluded that a greater emphasis is placed on liaison, consultation and joint working with other agencies.
\end{abstract}

In the past, mental health services for children with learning disabilities in York were separate from other child mental health services. They were provided in a patchwork way coordinated by the multi-disciplinary 'service for people with learning disabilities' and a clinical therapies directorate including psychology services. Over the years the services for children with learning disabilities evolved and were gradually eroded. The waiting-list reached 1 year and had to be closed. Many referrers became dissatisfied with the service and began to refer out of the district. In 1997 the provision of mental health services for children with learning disabilities was identified as an unmet need with respect to the Children's Charter (Department of Health, 1996). North Yorkshire health authority responded to concerns raised over the lack of services for these children by commissioning the Nuffield Institute for Health to undertake an assessment of need (Waddington \& Moore, 1998). Social services and education services were keen to develop cross agency services and were requesting a variety of mental health interventions.

In response to these circumstances York Child and Adolescent Mental Health Service (CAMHS) Directorate, based at Lime Trees, proposed the following: (a) a new integrated multi-disciplinary service with good multi-agency links

(b) that any new provision should recognise that ". . . the(se) children are among many with diverse special needs and should be provided for as children first and people with a particular disability second" (McKay \& Hall, 1994)

(c) that the management of the new childhood learning disability mental health service should be placed within the CAMHS Directorate in the York NHS Trust. This directorate includes multi-disciplinary services for children.

\section{Funding}

In June 1998 the CAMHS Directorate applied to North Yorkshire Health Authority for a fund of $£ 62000$ to develop a service for children with learning disabilities. In September 1998 the money was awarded from the Government's waiting-list initiative, and the CAMHS for learning disability was initially established on 1 January 1999, with all members of the team in place by April 1999. It should be noted that the posts of the community nurse and two sessions of clinical psychology time existed prior to the new funding and that the 
money given by the health authority was to cover the new posts only.

\section{Aims}

The aims of the service were:

(a) to provide an effective and efficient multi-disciplinary service with good inter-agency links for children with learning disabilities and their families

(b) to reduce the waiting-list from over 1 year to 3 months, within 1 year

(c) to increase the quality of care given to children and families

(d) to provide an integrated consultation and liaison service

(e) to provide group and family work

(f) to decrease the amount of out of county referrals and residential placements.

\section{The service}

\section{Staff}

Child clinical psychologists, 1.2 whole time equivalent (WTE), community nurse, 1.0 WTE, occupational therapist, 0.5 WTE, consultant child and family psychiatrist, 0.2 WTE, and secretary and reception staff, 0.5 WTE.

\section{Starting up}

Over 40 professionals from various disciplines and parents of children with learning disabilities were invited by the CAMHS learning disabilities team staff to attend a meeting in January 1999. This was a cooperative exercise to discuss potential options for configuring the service in view of limited resources. At the meeting, attendees completed a questionnaire (generated by the new team staff) that listed possible services that the team could potentially provide. They were divided into four groups of 10 and, through discussion, asked to reach a decision about the level of priority they felt should be given to each service. These were then collated and the summary of the prioritised service is shown in Box 1. The team members are of the view that the process, as well as the product, of this meeting was extremely valuable. It laid the foundation of the service aimed at creating strong inter-agency links as well as the need to be open about, and include other agencies in, decisions about resource allocation based on their needs. It also helped to introduce models of consultation and liaison, as well as work with individual families.

\section{Referral criteria}

The team takes referrals from general practitioners (GPs), hospital doctors, school doctors, health visitors, educational psychologists, behavioural support teachers and social workers. The child must exhibit one or more of the following: moderate to severe developmental delay; attendance at a special school; and/or autism spectrum disorder.

\section{Operational policy}

The team operates as a tier 3 service within CAMHS (NHS Health Advisory Service, 1995). It offers support to tier 1 professionals (such as teachers, health visitors, paediatricians, etc.) who often have daily contact with the client. The services provided by the team include individual care plans, where the team work with the individual and family on issues such as behaviour management and where cases are complex; co-working, group work, etc. Weekly meetings are held in which the team discusses development, supervision and current issues.

\section{Box 1. Prioritised service provision for the child and adolescent mental health service learning disabilities team}

1. Assessment and treatment of child mental health problems in children with learning disabilities referred to Lime Trees.

2. Some involvement in the assessment and treatment of child development centre children; those with complex problems where there is a mental health component.

3. Offer behaviour management advice to families.

4. Teaching and training within special schools.

5. Attendance at autism spectrum disorders forum.

6. Some input to social services, co-working with other professionals providing interventions for children and their families where there are child mental health problems.

7. The formation of a multi-agency learning disability team including professionals from other agencies (e.g. paediatrician, educational psychologist, social workers, school doctor, etc.).

8. Consultation and liaison with staff within each individual special school.

9. Close links with paediatric and child health teams.

10. Teaching and training to other agencies.

11. Close links with the adult learning disability service.

12. Presentations/discussions/liaison with parent support groups.

13. Input to child development centre.

14. Family therapy.

15. Consultation to staff within social services offering respite care facilities.

16. Audit.

17. Organisation and running of groups for children (e.g. social skills groups). 


\section{Audit of CAMHS learning disabilities service after 8 months}

original

papers

\section{Sample}

In all, data were collected on 111 children who were seen by the CAMHS learning disabilities team from 1 January 1990 to 31 August 1999. The mean age of the sample was 9 years ( $\operatorname{mode}=4$ years; s.d. $=4$ years). Seventy-one per cent were males and $29 \%$ female. Six (of 111) failed to attend their initial appointment (5\%). Fifty-six (53\%) were referred after 1 January 1999 and 49 (43\%) were on the waiting-list.

\section{Referral patterns}

Overall, 43 different referrers were identified. These included GPs, paediatricians, social workers and educational psychologists. The majority of referrals were made by paediatricians $(51 ; 45 \%)$. In all, the team recorded 569 hourly direct contacts between 1 January 1999 and 1 September 1999.

\section{Referral requests}

A wide range of problems were reported in the referral letters for this sample of children. In total, 32 different requests were made with regard to input. The most frequent requests were for help with general behaviour problems (23; 20\%) and autism assessments (27; 24\%). Other large groups included communication problems, emotional distress and soiling problems. On the whole, most referrals were appropriate for the service, particularly as good communication and liaison systems developed with referring agencies.

\section{Autism spectrum disorders}

The most common disability affecting the children in this study was autism or a related condition. This is comparable to the figures quoted by the Nuffield Research Project (Waddington \& Moore, 1998). For example, they reported that 93 out of 200 (47\%) children in their study were affected by autism or a related problem. The prevalence of autism spectrum disorders in our sample is 42 (40\%).

\section{Special school attendance}

Just over half of the children attend special schools (63; $58 \%)$, which is rather low compared to the findings of the Nuffield, where 175 (88\%) children attended special schools/nurseries. However, 17 (16\%) in our sample were either pre-school age or home-educated. The remaining 29 (27\%) were in mainstream school with high levels of support. Some of these children had a diagnosis of Asperger's syndrome or high functioning autism, while others had various disabilities and were integrated into mainstream schools.

\section{Complex cases}

Seventeen per cent of the sample were discharged at the time of the study, suggesting that cases are complex and enduring. In fact, the nature of this client group makes discharge very difficult. Children's problems could be complex, multi-faceted or persistent and many children developed new difficulties as old ones disappear. Many parents require time and support in coming to terms with the losses associated with having a child with a permanent disability. Some parents, including those who have learning disabilities themselves, need advice throughout the child's developmental stages.

In order to address the potential problem of waiting-lists being generated by low discharge rates, the team is currently operating a policy of working in a goal directed manner with the view to take families off our case-loads once the goals have been achieved. Additionally, the team refers to tier 1 agencies, including health visitors, family workers, family centres, autism specialist workers and special needs coordinators who carry out specific individual work and take on a supportive role. The team offers consultation and liaison services as appropriate, which a number of tier 1 agencies have found helpful. It is recognised, however, that in a small number of cases it may be necessary to work with families on a 'maintenance' basis in order to avoid family crises.

\section{Liaison and consultation}

Time spent in liaison and consultation work was not accounted for in this audit, although this is a large part of the team's work. Following the multi-agency meeting in January, liaison and consultation occurs regularly with special school staff, social workers, educational psychologists, paediatricians, speech therapists and respite care facilities.

\section{CAMHS involvement}

At least 11 members of the wider CAMHS, who are not part of the learning disability team, have become involved with the children in the sample. This represents a willingness and interest in sharing skills and services to the benefit of children and families. The advantage of placing this service within an existing multi-disciplinary CAMHS is that children with learning disabilities have access to other Tier 3 teams including family therapy, an attentional problems team, an eating disorders team, a groups team and other expertise.

\section{Waiting-lists}

Waiting-lists have been reduced from 1 year to approximately 1 month. However, waiting times are beginning to grow as the team take on increasingly large numbers of cases without discharging cases at an equal rate. 


\section{Attendance}

The finding that only 6 children and their families failed to attend for their initial appointment is encouraging and shows a much higher attendance rate than for local CAMHS in general (19\%), which is also in keeping with child mental health services in general (Mason et al, 1995). This strengthens the belief that referrals are appropriate and that cases are needy.

\section{Shared expertise}

It is an advantage to have a multi-disciplinary team with shared expertise, and having a range of training options. With respect to psychiatry, we know that some postholders around the country will have dual training in child psychiatry and learning disability. More commonly, consultants take on responsibility for such services after training in child psychiatry with some expertise with learning disabled children. The College makes neuropsychiatry and developmental disorders experience an essential requirement for a Certificate of Training to be issued, and we would urge training schemes to make this training robust (Child and Adolescent Psychiatry, Specialist Advisory Committee Advisory Papers, November 1999, available upon written request from The Postgraduate Education Services, The Royal College of Psychiatry, 17 Belgrave Square, London SW1X 8PG). Similarly, other disciplines within the team should have a training that is appropriate for their role, and careful consideration be given to job descriptions in this regard.

\section{Conclusions and future work}

The team has achieved its original aims:

(a) To reduce the waiting-list from 1 year to 3 months within 1 year. The mean waiting time is now 29 days.

(b) To provide an integrated consultation and liaison service. Regular, formal consultation occurs with social services, educational psychology services, paediatricians, headteachers and special education needs coordinators from the special schools and respite care facilities. (c) To provide group and family work. The team offers group work (anger management, daily living skills, self esteem, social skills) and family therapy.

(d) To decrease the amount of out of country referrals and residential placements. There was one out of county placement made between January 1999 and September 1999. This was a child with autism who required residential care that was not available locally. There have been no other out of county referrals.

The team plans to complete a survey of user satisfaction and to devise a method for the collection of indirect activity, such as consultation. The audit has highlighted concerns about large case-loads owing to the difficulties entailed in discharging some cases. It also emphasises the need for liaison, consultation and joint work with other agencies as a means of providing an effective and efficient multi-disciplinary service for children with learning disabilities and their families (Black et al, 1999). In terms of a service model this tier 3 team within a CAMHS team is proving to be a useful model with the advantages of considering children as 'children first' (their disability secondary), offering a multi-disciplinary approach and, with its emphasis on liaison and consultation, providing good continuity into adult service provision.

\section{References}

BLACK, J., WRIGHT, B. J., WILLIAMS, C., L Learning Disability (Mental Handicap). et al (1999) Paediatric liaison service. London: British Paediatric Assocation. Psychiatric Bulletin, 23, 528-530. NHSHEALTH ADVISORY SERVICE (1995) DEPARTMENT OF HEALTH (1996) NHS. Together We Stand. Child and The Patients Charter. Services for Adolescent Mental Health Services. Children and Young People. London: London: HMSO. Department of Health. of children who have severe learning and adolescent psychiatric out-patient and Psychiatry, 1, 581-596. service. Association of Child Psychiatry and Psychiatry Review and Newsletter, 17, 313-322.

WADDINGTON, E., \& MOORE, J. (1998) Children with Learning Disabilities and Severe Challenging Behaviour. Leeds: McKAY, I. \& HALL, D. (1994) Services Nuffield Institute for Health. for Children and Adolescents with

Kath Green Trainee Clinical Psychologist ～*Chris Williams Clinical Psychologist, Ian Partridge SocialWorker, Barry Wright Consultant Child Psychiatrist, LimeTrees Child, Adolescent and Family Unit, 31 Shipton Road, YorkY030 5RF; tel: 01904652 908; fax: 01904632893 